\title{
NALLD SCAN
}

\section{Stephen Spangehl}

Beginning with this issue, the NALLD Joumal: Technology and Mediated Instruction will present to its readers a new feature entitled NALLD SCAN. It is intended to be a critical digest of worthwhile articles and features which appear in other publications dedicated to educational technology. NALLD SCAN does not claim to be an exhaustive survey, but rather will hopefully introduce our readers to facts, ideas, and techniques, which could normally be acquired only through reading a veritable host of magazines and journals. As NALLD SCAN grows and extends its coverage, the editors are sure that the readers will learn to value it greatly.

Our readers are invited to become participating reviewers for NALLD SCAN. If you regularly read a publication which treats-even rarely-issues in educational' technology, please forward your name and the name of the publication to the Review Editor. Potential reviewers will be provided with guidelines for writing brief reviews of those articles which the editors feel would be of interest to the readers of the NALLD JOURNAL. Given enough "journal watchers", NALLD SCAN will become a powerful resource for all readers. NALLD SCAN reviews must be in English. However, the editors encourage readers of publications in other languages to digest and comment on the articles they wish to share.

\section{COMPUTER SOFTWARE FOR COLLEGE ADMINISTRATION}

Robert M. Delf, "Primer for Purchasing Software," AS\&U: American School \& University, (July 1981), pp. 44-45.

North American Publishing Co.

401 North Broad Street

Philadelphia, PA 19108

$\$ 25 /$ year (as of 9/81)

Most of us think of computers in terms of their instructional uses: computer-assisted instruction, computer-managed instruction, simulations, etc. However, most campus computers give priority to the less glamorous but necessary administrative jobs; instruction gets the time left over. Thus how well the computer is used for administration should concern us deeply. This series of articles (continued in the September and October issues) discusses the use of programs for academic record-keeping: admissions, registration, grades, mailing lists, etc. Delf, vice-president at Columbia Computing Services in Kent, Washington, reviews the process of deciding what software to purchase for these purposes-how institutions should analyze their needs, solicit bids, evaluate differing programs, and purchase supporting hardware. Though brief, the articles list many 
questions which administrators should ask before they commit their institutions to purchase a particular program package, questions which, in the long run, will benefit all those who rely on the central computer. Send your registrar a copy.

$$
\text { - Stephen D. Spangehl' }
$$

\section{COPYRIGHT}

"At Last (whew)! Off-Air Copying Guidelines." Instructional Innovator, (September, 1981), pp, 36-7.

In March, 1979, Congressman Robert Kastenmeier, Chairman of the House subcommittee that deals with the area of copyright, appointed a committee to deal with the development of a set of guidelines for off-air recording by instructional institutions: an area not covered by PL 94-553, the new copyright law.

Following is an outline of the final guidelines:

1. Applicable only to off-air recording by non-profit educational institutions.

2. Broadcast programs may be recorded off-air and retained by the institution for forty-five days or less after the recording date.

3. Individual teachers may use off-air recordings once, and repeat once for reinforcement, in instructional settings and in homes, for homebound students, during the first ten consecutive school days in the forty-five day retention period.

4. Off-air recordings may be made only at the request of and used by individual teachers; no program may be recorded more than once for the same teacher.

5. A limited number of copies may be made from each recording to meet the demand of teachers.

6. The recording is to be used only for teacher evaluation purposes after the first ten consecutive school days period.

7. Recordings may not be altered from their original content.

8. The copyright notice must be included on each recording.

9. Appropriate control procedures to maintain the guidelines must be used by the educational institution.

Karen MacGregor

Graduate Assistant, Department of Special Education, University of Louisville.

\section{LEARNING LABORATORY FURNITURE: CARRELS}

Judson Swith, "Study Carrels: From the Ancient Greeks to Interactive Video," Training: The Magazine of Human Resources Development (February, 1981), pp. 58-63.

For $\$ 30$ you can purchase a table-top separator "like one of those 
reflector units sun worshipers use to catch rays." Expensive, wired, freestanding carrels can cost $\$ 400$ and up. This article lays out the factors that ought to influence your choice with a series of intelligent questions for need analysis. Smith discusses intended function, construction, safety and abuse-will someone sit on it?-and a number of other considerations: adaptation to future use with microcomputers, interactive video, etc. This is a good, general piece for those contemplating the purchase of carrels, but it never gets to specific recommendations, nor does it list the names of suppliers.

- Stephen D. SpangehI

\section{TELEVISION PROJECTION}

Ingrid Wiegand, "Large-Screen Video Projection Systems," Video User (August, 1981), p. 16.

Is bigger better? Anyone who has shown a videotape to a class of fifty using a single 19 inch monitor knows the problems of small screens, but a logical analysis will demonstrate that the six-foot projection TV screen must still contain the same pattern of $\mathbf{5 2 5}$ lines. Wiegand confirms this: shown on a large screen, minor production flaws and static become major distractions, while image quality degenerates unless the viewer retreats twenty foot from the screen. She does, however, discuss the emerging technology that helps to conceal these flaws in resolution (the "comb"), and presents a sensible discussion of curved versus flat screens (curved for small groups only). Though she does not recommend a video projection system outright, she does name manufacturers, models, and prices, and comments guardedly on their relative merits. One's overall impression is that the purchase picture is still fuzzy; so keep on squinting at the small tube and wait.

- Sephen D. Spangehl

\section{TV AND RADIO LICENSES AND OWNERS}

"For the Record," Broadcasting (September 28, 1981), pp. 60-64.

Broadcasting Publications Inc.

1735 DeSales Street NW

Washington, D.C. 20036

$\$ 50 /$ year (as of 9/81)

"For the Record" is a regular feature in the weekly Broadcasting. It lists, in four or five pages of small type, a wealth of information concerning changes in the broadcasting industry, and can provide the educator with an early introduction to new stations, new owners, and new services in his area. The listings include AM, FM, and TV applications (with names, addresses, estimated costs and revenues); licences granted or denied; 
applications and actions relating to changes in ownership; facility and frequency changes; frequency allocations; new cable systems; and earth stations (satellite/community antenna applications and actions). Radio, broadcast television, and cable television can extend educational services to those who might never use them otherwise; knowing who owns what (or who will own what) can allow the educator access to the commercial media-for airtime, for production facilities, for advice. Scanning this Broadcast feature regularly is worth the time it takes.

\section{- Stephen D. Spangehl}

\section{VIDEOCASSETTE RECORDERS}

"Dusting Off Your VCR: Why Educators are Taking a Second Look at Videocassette Recorders," Electronic Learning (September/October, 1981), pp. 35,64.

This article, intended for secondary school teachers, outlines some of the major obstacles to wider educational utilization of VCR's, and suggests that the new technology of interactive video will encourage use in the future. Four manufacturers and systems are named, but no data are given; this is not a guide for buyers, but merely a brief overview of the potential merits of an important new development in instructional technology.

\section{- Stephen D. Spangehl}

\section{VIDEO PRODUCTION: BUDGETS}

Michael J. Bashista and Judson Smith, "Making the Best Budgeting and Production Trade-Offs," Training: The Magazine of Human Resources Development (August, 1981), pp. 37-40.

Lakewood Publications, Inc.

731 Hennepin Avenue

Minneapolis, MN 55403

Bashista, Region V director of the International Television Association, and Smith, an audiovisual consultant, present the basic considerations to be used in budgeting video productions. Writing for a business audience interested in making instructional training tapes, they stress the point that other media, though less fashionable than video, are often preferable in terms of cost, time, and trouble-a hard fact too frequently overlooked. Their discussion of video budgets is clearheaded, particularly when they speak of the need to honestly estimate the quality needed in the production. Not all video needs to be of high quality, they claim; if a less professional tape will serve your purposes, it's better to save costs than insist on high production values for their own sake. They go on to outline other "trade-off" considerations: site (studio versus location 
shooting), talent (professional versus amateur), audio (lip sync versus voice-over narration), graphics, and format. As hard-nosed budgeters, they even remind us not to neglect the "hidden" extras: props, costumes, rehersal time. Not all of their considerations translate to educational settings, but enough do to make this piece very useful in production planning. A concise yet complete form for video budgeting is included; many readers will wish they had had an opportunity to think through each item before their last video production effort.

- Stephen D. Spangehl

\section{VIDEO PRODUCTION: USING SLIDES}

Grant Williams, "Shooting Slides for Television," Video User (August, 1981), p. 4.

Knowledge Industry Publications, Inc.

701 Westchester Avenue

White Plains, New York 10604

$\$ 20 /$ year (as of $8 / 81$ )

In this short but very useful article, Williams, who regularly writes the "Production Techniques" column for Video User, gives sensible advice on using slides in videoproduction. He begins and ends with a warning: video is too flexible for its own good, and a thoughtless incorporation of film, slides, artwork, and audio sources can make the resulting tape a "patchwork quilt." A good use of slides on video, he claims, is the series of tinted stills used to introduce the old "Saturday Night Live." If you feel slides are appropriate for your purposes, his tips are worth following: (1) Use a medium ASA film, like commercial Extachrome (known as ECO, available in bulk); Kodachrome is too contrasty for video, but Ektachrome ASA 64 is a workable alternative to ECO. (2) Shoot everything in horizontal format, and allow for video loss; $35 \mathrm{~mm}$. is in $5: 7$ ratio, video in 3:4. (3) Avoid busy photographs; keep a single center of interest, or guide the viewer's attention through selective focusing. (4) Shoot slides in sequences, and use them that way to create an illusion of movement-wide shots, medium shots, close ups; a motordrive can make this easy.

- Stephen D. Spangehl 


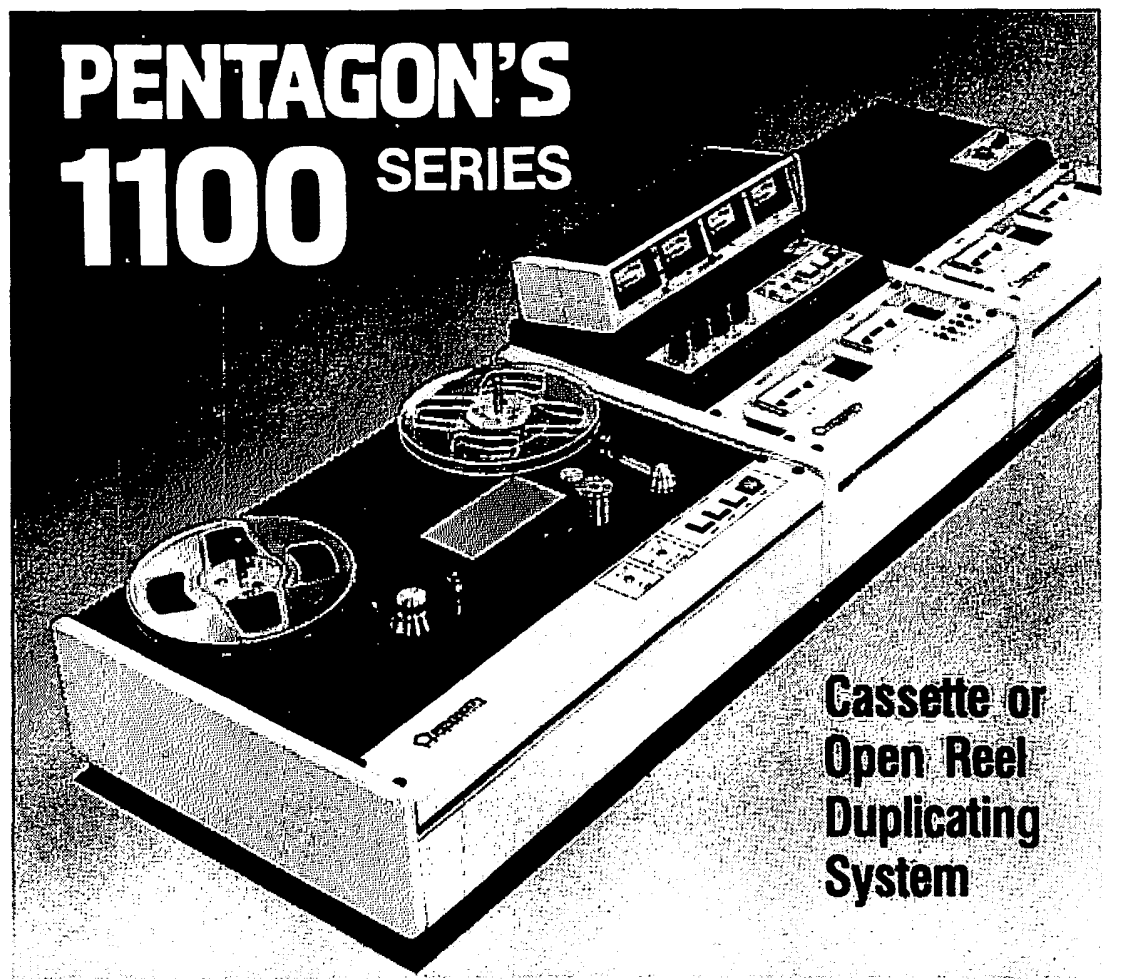

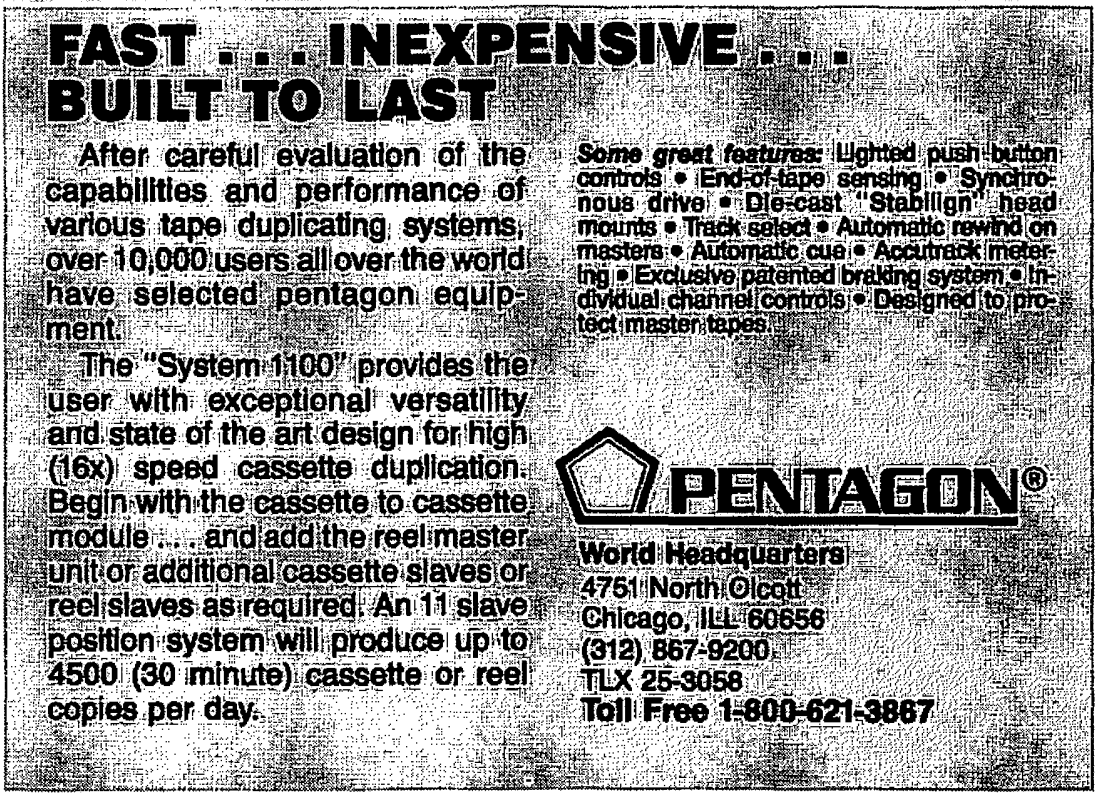

